\title{
A monumentalidade na democratização do espaço e da cultura
}

\author{
INÊS ALVES
}

\section{Resumo}

O artigo propõe uma reflexão sobre monumentalidade no instaurar do poder político e religioso, e sua reconversão com uma sociedade democrática. São analisadas $3+1$ tipologias de espaço expositivo cultural: o palácio ou a igreja, contentores de grandes obras de arte clássicas, no miolo dos centros históricos; as galerias de arte associadas a uma economia mercantil, com dinamização de uma zona do centro da cidade e ainda, a autonomização do objeto arquitetônico na proximidade da cidade tradicional. Por último é referido o estudo de caso -

Palavras-chave: Democratização, espaço público, monumentalidade Silo Espaço Cultural - no interior do NorteShopping, porém disposto numa estrutura periférica a este, que se vem distinguir por uma aparente proximidade a público múltiplo. 


\title{
Monumentality on space and cultural democratization
}

\author{
INÊS ALVES
}

\begin{abstract}
The article proposes a reflection on the idea of monumentality in political and religious power, and its reconversion of a democratic society. There are $3+1$ types of cultural exhibition space that are analyzed: the traditional palace or the church, which contain great works of classical art, inside of the historic centers; the art galleries associated with market economy, tend to stimulate the city centre area, and the autonomy of the architectural object in the vicinity of the traditional city. Lastly it is referred the case study - Silo Cultural Space - inside the Norteshopping, but arranged in a peripheral form, which is distinguished by an apparent proximity to multiple public.
\end{abstract}

Keywords:

Democratization, public space, monumentality 


\section{La monumentalidad en la democra- tización del espacio y de la cultura}

\section{INÊS ALVES}

\section{Resumen}

El artículo propone una reflexión sobre monumentalidad en el instaurar del poder político y religioso, y su reconversión con una sociedad democrática. Son analizadas $3+1$ tipologías de espacio expositivo cultural: el palacio o la iglesia, contenedores de grandes obras del arte clásicos, dentro de los centros históricos; las galerías del arte asociadas a una economía mercantil, con dinamización de una zona del centro de la ciudad y aún, la autonomización del objeto arquitectónico en la proximidad de la ciudad tradicional. Por

Palabras clave: Democratización, espacio público, monumentalidad último es referido el estudio de caso - Silo Espacio Cultural - en el interior del NorteShopping, todavía dispuesto en una estructura periférica a este, que se distingue por una aparente proximidad al público múltiplo. 


\section{A compressão e descompressão espacial}

Desde muito cedo, a arquitetura se imporia como forma de monumentalidade e de poder. Poder político ou poder clerical seria símbolo de grandiosidade e de redutibilidade do 'homem' a uma insignificância física e mental. Apenas os sentidos e emoções estariam aqui presentes por parte do indivíduo comum, ora como que extasiado com a presença de tal imponência, ora esmagado pela força que tal escala trazia, personificando um poder individualizado, daquele que estaria por detrás do seu planejamento.

Evidentemente, a par da arquitetura, também as outras tradicionais "beaux arts" apresentavam o intuito da eternização da nobreza e burguesia, de forma idealizada.

A escultura, por sua vez, vem contribuir com a tridimensionalidade da figuração, que permite a criação à escala humana ou proporcionalmente superior a esta, sempre elevada sobre o plinto, sobrepondo-se assim aos seus observadores. A monumentalidade seria aqui marcada de forma muito mais individual, servindo mais um personagem em particular e não só apenas um poder institucional.

A arquitetura, desde sempre entendida como disciplina que pretendia dar abrigo e habitabilidade ao ser humano, permite trabalhar sobre esta dinâmica, albergando em si os indivíduos, mas transformando-se ainda em relação com o exterior, sob frente urbana e referencial.

Na comunicação com o exterior, o seu plano de fachada surgia como uma enorme tela sobre a qual se poderia contar uma história ou transmitir uma mensagem, fosse ela sobre poder (1), êxtase (2) ou mudança (3). Exemplificando podemos recordar os palacetes dos Medici espalhados por Florença (1), com a sua demarcação na fachada dos espaços de serviço - numa superfície 
rude, com a pedra pouco trabalhada e com relação mínima entre o interior/exterior - e dos espaços da burguesia - com uma pedra lisa e trabalhada; as fachadas das igrejas barrocas espalhadas um pouco por toda a Europa (2), como seria o caso da Basílica de Santa Croce, em Lecce, na qual a monumentalidade da fachada que se sobrepõe à dimensão interior e original do espaço arquitetônico; ou ainda dissolver do traçado orgânico e medieval de Paris (3), com a reestruturação urbana levada a cabo por Haussmann, com ruas abertas e novos espaços públicos, que marcam uma nova posição social.

Inicialmente com a revolução industrial, observamos o crescimento do proletariado e a falta de habitabilidade generalizada por este estrato social. A arquitetura deixa aqui de se conseguir concretizar como abrigo e habitabilidade do indivíduo. São consideradas prioridades de quantificação, em detrimento da qualidade. Essa condição volátil e condicionada do 'homem', vem pela primeira vez, colocar em questão fenômenos desconhecidos anteriormente de deslocalização, com um êxodo rural marcante, a par de uma condição precária e descrente.

Seria o início de uma decisiva evolução técnica e tecnológica. A fotografia viria deitar por terra o objetivo realista e de eternização da pintura, que se torna desde esse momento, conceptual e crescentemente abstrata. A escultura perderia o plinto inicial, colocando-se claramente de frente ao espectador, não mais pertencente apenas a uma classe burguesa, mas cada vez mais múltipla, com o estabelecer de uma sociedade tendencialmente democrática, com acesso generalizado ao objeto de produção e, por conseguinte, aos espaços públicos e atividades cívicas quotidianas. A pujante exigência democrática que marca a história ocidental, em especial no último centenário, vem exigir uma igualdade de sexo, etnia e cultura, que se acentua na escultura de forma notável, com uma igualdade de escala e de patamar. Será de recordar as grandes estátuas de ditadores do médio oriente, em especial a de Saddam Hussein, com dimensões majestosas e sobre um plinto também ele majestoso, que vem a ser derrubada em protesto, em abril de 2003.

Por outro lado, o conceito de "expanded field" vem chamar a atenção para um empolar do espaço de intervenção da escultura, vindo a originar tipologias várias como a "land art" ou a "environmental art", que se viria a impor com uma tomada de consciência ecológica e finita do mundo.

$\mathrm{Na}$ arquitetura, o que se observa, inicialmente com o "movimento moderno", seria - tal como a escultura - a ideia de que o "homem" serviria de medida para todas as coisas. A reinven- 
ção dessa ideia humanista, observada com o "homem de Vitrúvio", de Alberti ou de Leonardo DaVinci, impõe-se aqui pela mão de Le Corbusier que vem definir aquilo a que chamaria de "Modulor" (1943), um sistema harmônico entre as medidas do "homem" e o seu ambiente - seus habitats, utensílios.

A revolução industrial de que se falava é pensada pelos arquitetos deste tempo, pela imposição de um modelo industrial e materializada por formulações de cidades de raiz, de que é exemplo a "cidade industrial" de Tony Garnier (1918). Essa teria como modelo a cidade de Lyon e permitia albergar aproximadamente 35 mil pessoas, dando-lhes acesso à habitação, ao trabalho, lazer e cultura. Nesse período, a cidade ideal pensada por Le Corbusier possuiria uma dimensão altamente utópica, nomeando-a de "cidade contemporânea" (1922) e que dava acesso a um total de três milhões de habitantes. Era aqui privilegiada uma dimensão novamente monumental, tendo em conta o progresso e o investimento num futuro promissor, com grandes arranha-céus e espaços empresariais, a par de uma referência essencial às vias de comunicação, com alusão à velocidade e um novo olhar sobre a manipulação espaço e temporal.

Num clima de pós-guerra, o contributo de Le Corbusier prende-se com a reconstrução das cidades, nomeadamente de Marselha, na qual coloca em prática o modelo de "cidade radiosa” (1947), dispondo a habitação num grande edifício imponente, de referência visual, que, no entanto, sobressaem pela sua dimensão de qualidade habitacional, com condições de arejamento e exposição solar nunca antes democraticamente pensadas.

A monumentalidade é aqui trazida até ao homem comum, que passa não só a deparar-se urbanamente com uma escala esmagadora, mas que também habita esse mesmo espaço, usufruindo de uma relação privilegiada entre aquilo que é a relação urbana do edifício imponente com a cidade e o espaço de habitação à sua escala, que o acolhe e o abriga, com as melhores condições possíveis.

\section{Referência}

Esta alternância espacial traz, desde sempre, uma preocupação referencial que se agrava num período de expansão das tecnologias de informação, compressão das relações espaço/ tempo e de homogeneização cultural.

Apenas em 1995, viria Augé alertar para aquilo que seriam 'não-lugares', pela carência referencial que os espaços assumiam 
de forma crescente e descontrolada. Espaços comuns e transitórios, como os de aeroporto, gare, estação, mesmo os de centro comercial ou de quarto de hotel, possuidores de uma estruturação cumpridora de parâmetros universais, dispondo-se perante sujeito como "simulacro" (Baudrillard, 1981) de cidade tradicional.

As questões da monumentalidade e da referenciação apresentam-se fundamentais desde que a intencionalidade pública da arquitetura se observou.

A par dos picos de monumentalidade que se foram observando ao longo da história, a questão da referenciação que surgia na estruturação urbana, associando ruas com praças e largos e pensando novos enquadramentos visuais e encenações urbanas, bem como novas identificações dos habitantes com as suas cidades.

Com base num pensamento moderno, de produção em série e modular, as grandes estruturas urbanas, que foram surgindo com o estabelecer de uma sociedade pós-moderna capitalista, obedeciam a esse modelo de reprodução cognitiva, que reduzia ao mínimo a atenção do seu utilizador para o percurso a realizar.

A estruturação de grandes superfícies de transporte, de compras ou de dormida sazonal vem assumir mais uma vez uma imponência característica que não cumpre já funções de referencial ou de associação a um poder institucional totalitário. Essas grandes estruturas necessitam servir agora uma quantidade massiva de sujeitos, segundo um ambiente que procura estabelecer o melhor padrão qualitativo possível. Para além disto, assumem ainda pontos autorreferenciados, que não estabelecem já uma referencia visual urbana de grande importância, mas que se autonomizam na paisagem e localização, fora das cidades tradicionais, onde a construção de grandes dimensões se torna possível, e que funcionam como apenas mais um elemento entre muitos outros, no estruturar de uma malha de interconexões que servem o acesso à mobilidade, aos produtos e serviços.

A referenciação torna-se, portanto, autônoma e isolada frente à cidade que servia anteriormente um poder e uma própria referenciação visual, passando para fora dos limites considerados outrora urbanos e respondendo agora a uma rede de elementos georreferenciados e ao seu papel no interior desse mesmo esquema.

A imposição de uma sociedade pós-moderna e banalização de uma economia de mercado vêm traduzir-se nas artes com o surgir de novas tipologias artísticas, não mais correspondentes às tradicionais "beaux arts", mas notavelmente mais abrangen- 
tes como a arte pública ou a "street art", que de alguma forma trazem até à cidade tradicional um novo sistema de referências, ao qual o cidadão pós-moderno acede de um modo automático e desenvolve um sentido crítico nunca antes no seu domínio. Os media vêm democratizar a imagem e o acesso ao conhecimento, dando a conhecer que se passa por todo o mundo. As referências existentes a partir desses tempos são tão múltiplas quanto tendencialmente homogêneas, com um aparente achatamento universal do saber, das distâncias ou da própria presença, que se torna relativa. Apesar da ideia de homogeneização existe a possibilidade de um indivíduo ou sociedade passar a adquirir identificação com os atentados aos direitos humanos no Oriente Médio ou a fome na África. Culturalmente observa-se uma referência daquilo que são os valores Europeus, com acesso à educação, saúde, e transportes coletivos, ou mesmo ocidentais, com o direito ao trabalho e à igualdade de sexos e proveniências.

A referência deixa assim de se compor por aquilo que se estabelece na cidade tradicional como elemento físico e enquadramento visual, mas adquire agora lugar numa rede georreferenciada de acesso aos espaços de imponência massiva (1), ou ainda como espaço aberto, mental ou cognitivo, de acesso à cultura, ao conhecimento ou à arte, pelo acesso à imagem, conseguido pelos medias ou pelo deslocalizar da arte para fora da galeria comercial (2).

\section{Exposição e imposição}

A monumentalidade daquilo que seria encomendado aos grandes artistas da época, para as monumentais igrejas ou palácios, por parte dos seus regedores e proprietários, traria até hoje espaços notáveis de exposição das mais marcantes peças da arte clássica. Edifícios como os Museus do Vaticano ou o Museu do Louvre são contentores das grandes heranças culturais com que a história nos caracteriza, trazendo sempre em si, símbolo de poder e de glória.

A pós-modernidade, que vem cortar com toda a ideia historicista do local e da monumentalidade do poder, traz em si novas possibilidades, resultantes de uma forte necessidade de cortar com o poder outrora pertencente a uma camada restrita da população, inacessível à obra de arte ou condicionada ao espaço exterior por meio da frente urbana.

Um dos primeiros fenômenos observados com a democratização da imagem, protagonizada em grande parte pela televisão e traduzida pela banalização desses mesmos, materializada 
com uma manifestação de acesso, sob um estilo apelativo aos sentidos, combinando diferentes estilos arquitetônicos, com cores exuberantes e sempre que possível, presença das tecnologias em expansão, como leds que referenciavam e atraiam a atenção, ou ecrãs, que de alguma forma sacralizavam a televisão e as possibilidades que com ela se impuseram.

Num período de pós-guerra e entendimento da volatilidade humana, seria imperativo um estado festivo que de alguma forma alienasse o estado de consciência das coisas e do "eu".

É de chamar a atenção o acompanhar desse impacto na arquitetura pelo já referido empolar do espaço de intervenção do artista, desde o atelier à rua e paisagem, cumprindo em grande parte, questões relacionadas com o conceito de "campo expandido", que vem dessacralizar a obra de arte em si.

É importante ainda referir a importância da marcação da rua, através da "street art" como elemento de ocupação dos subúrbios das grandes cidades, que cresciam de forma desmedida e que, mais uma vez, não possuíam no seu imediato as condições necessárias de habitabilidade. Fomentada em grande parte por gangs que reclamavam para si espaços públicos de cidade, serviam ao invés para desfragmentar o território em variados espaços marginais, muitas das vezes marcado por confrontos entre grupos rivais. No entanto, o percurso realizado pela "street art" vem alterar as suas motivações, conferindo-lhe qualidades estéticas e formais, que frequentemente traduzem preocupações e críticas sociopolíticas.

A par desta dimensão de manifestação e reclamação de espaço que deixa de ser o do espaço público marginal e não qualificado, passando a ser o de um espaço de todos, pela justiça social e política, igualdade e acesso de todos à arte que se faz pelas ruas.

Vai sendo aqui erigido um novo conceito, que vem colocar em questão o artista como manifestante social, contra o elitismo do espaço expositivo e o poder de um conhecimento cultural e artístico, que se torna mais acessível e necessariamente democrático. O contrapoder dos detentores do conhecimento, novos burgueses, aqueles que têm a possibilidade de frequentar as melhores escolas e de se fazer rodear pelas "melhores" influências, em prol de uma arte conceptual ou apelativa aos sentidos, distinguem-se dos demais pela colaboração e aceitação do sistema em que a arte e o seu comércio se inserem.

Com tão grandes questões socioeconômicas a moderar o quotidiano, observa-se um crescente número de artistas de rua e espaço público, que reclamam o estado alienador do 
sistema como máscara, imposto mais uma vez por um poder. Agora, é o poder do conhecimento, que vem manter exclusivamente no interior da galeria a "obra de arte", cumpridora também de uma economia de mercado, na qual a dimensão reflexiva se esbatesse nas suas formulações.

O próprio conceito de 'galeria' é, no entanto, já mais fluido na cidade tradicional, ao contrário dos grandes museus que se impõem por uma forte linguagem e escala.

Como herança do movimento moderno, observamos aqui, mais uma vez, uma tipologia de zoneamento, com a colocação de galerias de arte num quarteirão ou rua da cidade tradicional, com uma proximidade singela e harmoniosa, para que o público desses espaços possa caminhar entre eles de forma fluida, em que a cadência entre o interior e exterior funcione como momento reflexivo e de transição entre as diferentes tipologias apresentadas.

O fenômeno a que se assiste na Rua de Miguel Bombarda, no Porto, é exemplo deste mesmo zoneamento e cadência entre os espaços que fluem entre o interior e o exterior. Neste caso, também Miguel Bombarda protagoniza um forte período de dinamização sociocultural do centro histórico e baixa do Porto, no qual esta rua de galerias constitui mais um ponto de visita assídua por parte dos moradores da mancha urbana do Grande Porto. A par dos mercados - Clérigos, Porto Belo, entre outros - nos quais são explorados o "artesanato urbano" e as novas "indústrias criativas", também Bombarda representa espaço de passagem obrigatória em sábado de inauguração de exposições, com uma grande máquina publicitária em funcionamento. Espera-se chegar ao maior número de visitantes, ultrapassando barreiras culturais e apelando a aos sentidos, com animação de rua e presença de grandes marcas de bebidas que se aliam para quebrar barreiras, entre os conceitos de arte, cultura, pop, moda, marca, fanfarra, desfile. O ritual tem como objetivo fazer-se ver, como que existir neste meio e de alguma forma sentir que se faz parte e se identifica com a arte e com a cultura, num clima carnavalesco.

A verdade é que por esse mesmo ritual a democratização da arte atinge o seu auge na cidade do Porto, a par de um populismo exacerbado, que acaba por obedecer a um princípio já conhecido de segregação em que um zonamento colabora de forma incisiva. A colocação de espaços expositivos de arte na cidade tradicional vem levar a cabo de forma dissimulada o fenômeno de gentrificação, na verdade muito explorado pelas cidades medievais, hoje despopularizadas e que procuram a 
reconversão das suas gentes para um particular nicho populacional, de maior acesso econômico e cultural, que vêm 'abafar' de certo modo a raiz tradicional e popular desses locais.

São hoje privilegiados os espaços históricos da cidade tradicional e o que se passa é que a reconversão urbana vem requalificar e, dissimuladamente, gentrificar, colocando fasquias econômicas demasiado altas para que o acesso ao espaço habitado seja apenas acessível a um nicho muito reduzido da população.

O que se passa em Miguel Bombarda é também uma alteração dos costumes dos habitantes tradicionais desta rua. Os preços por metro quadrado disparam e assume-se a gentrificação. Quem tradicionalmente vive nestes espaços deixa de conseguir fazer frente às suas exigências e ainda pior, deixa de se identificar com esse mesmo espaço, que deixa de ser familiar, com mercearias de esquina, que se tornam ateliers de famosos criadores.

A visita ao espaço de Miguel Bombarda, apesar de ter sido já referido como importante na democratização da arte, é, no entanto, uma forma mascarada de o fazer. Quem visita esse território em 'sábados de inauguração', obtém 'sábados de festa', não interessando tanto a inauguração em si, mas a romaria que se estende para as ruas. A obra de arte, essa permanece no interior da galeria e continua a ser apenas acessível financeira e conceitualmente a uma elite reduzida.

\section{Nova monumentalidade}

Passados os tempos de ocupação dos grandes palácios como contentores das grandes obras de arte clássica, é, no entanto, fundamental que se entendam como elemento fulcral para a nossa identificação histórica e cultural. A sua monumentalidade, hoje acessível a todos, é esmagadora e complexa. Os percursos são labirínticos e permitem uma marcante impermeabilidade em relação ao exterior, quebrada por janelas cadentes e pontuais normalmente situadas em espaços de circulação. Os percursos são pensados a partir da planta existente, porém, com a adaptação de mecanismos de acesso ascendente e saídas de emergência, que facilitam a fluência do público na entrada e saída dos edifícios.

Essa adaptação representa aquilo que se verifica de forma generalizada pela arquitetura, desde a sua origem aos dias de hoje.

A reconversão das necessidades, aproveitamento do legado que nos é transmitido e dos recursos já existentes, a par de 
uma extinção ou redução ao mínimo dos usos originais, observa-se aqui uma adaptação de grandes palácios da nobreza, palacetes burgueses ou claustros de majestosas igrejas, a um uso expositivo de peças singulares que marcam determinado tempo na nossa história.

Tal como vimos, a galeria de arte na cidade tradicional virá condensar o espaço expositivo, sempre - ou na maior parte das vezes - associado a uma economia de mercado, na qual o artista, galerista e curador participam de um sistema de mercantilização da arte. Este paradigma não surge aqui de forma tão promíscua quanto aparentemente se perfila. Desde sempre, o artista, e de certo modo um feroz critico social, de posicionamento 'antissistema' ter-se-ia sujeitado à encomenda que ditaria a sua produção artística de maior escala e importância, correspondendo a uma motivação contraditória da sua convicção. Na realidade vemos que, desde sempre, a arte não vem corresponder a uma profissionalização tradicional, mas terá, no entanto, obrigatoriamente de fazer parte deste sistema econômico, que lhe permite subsistir enquanto artista e ser humano.

Um novo fenômeno foi-se estabelecendo com a euforia das grandes superfícies, herança da pós-modernidade, que junto das cidades tradicionais se estabelece de uma forma direta com o cotidiano, inserindo no dia-a-dia do cidadão comum a dimensão cultural, de forma massiva e majestosa.

Na década de 70, observamos em Paris uma materialização da dimensão pós-moderna no âmbito artístico, pela implantação de um edifício que funciona como uma grande máquina contentora de espaços culturais, teatros e biblioteca. O Centro Georges Pompidou, do arquiteto Renzo Piano (1977), ancora-se assim na área de Beaubourg e vem estabelecer quase que uma atitude provocatória perante à cidade de Paris, com a aplicação de uma arquitetura industrial, por meio de materiais estruturais que figuram na fachada do edifício, como os seus característicos tubulares metálicos. É aqui reclamado o acesso à cultura por parte de todos, com uma linguagem progressista e agressiva, que quase numa postura "pop" atrai os diferentes estratos socioculturais para uma estrutura quase de 'parque temático', onde podemos entrar de manhã e sair à noite, com toda a família.

Já na década de 9o, é inaugurado no país basco, na cidade de Bilbau, o Museu Guggenheim planeado pelo arquiteto Frank Gehry (1992), que vem estabelecer-se tal como a "máquina de Beaubourg" com certa proximidade com a cidade tradicional, dando o acesso generalizado à população, estabelecendo-se 
como ponto de visita turístico e acima de tudo, criando um impacto brutal com toda a envolvente. A proximidade ao rio permite a criação de uma dinâmica particular, novamente de referencial para frente urbana, mas ainda sugerindo um dinamismo da fachada quando visualizado de diferentes pontos de vista, nunca obtendo a mesma leitura, mas sempre reconhecendo na sua "pele" ou revestimento a grande estrutura de que se trata. A grande questão colocada com o Guggenheim de Bilbau foi a de se pretender estabelecer o "choque" com o resto da cidade, que em contraponto com o seu interior continua a conter espaços expositivos tradicionais e repetitivos.

Em Portugal seria de salientar o Centro Cultural de Belém (1989), do arquiteto Vittorio Gregotti, que apesar da sua singela presença, quando comparado com os exemplos anteriores, representou grande impacto na estrutura da cidade e frente urbana de Lisboa. A proximidade do CCB Lisboa à cidade tradicional e aos diferentes pontos de referência pré-existentes nesse território de grande importância histórica, como o Mosteiro dos Jerónimos ou a Torre de Belém, estabelece-se também ele como uma grande superfície constituinte de diversos espaços expositivos, de estar e de lazer.

Por último, é ainda referida a Casa da Música no Porto, de Rem Koolhaas (1999). O edifício não representa um museu na sua designação e acepção, mas vem já demarcar uma viragem na especialização das artes que se prefiguram. Esse edifício contém espaços de espetáculo, educativos, de lazer e refeição. A importância da Casa da Música prende-se de certo modo com as questões já referidas de proximidade à cidade tradicional, que cumpre um modelo democrático de acesso livre aos espaços, cruzando o lazer com o conhecimento.

Em qualquer um dos exemplos dados, observa-se uma transmutação da monumentalidade escultórica para fora do museu e da instituição cultural. O edifício deixa de ser apenas edifício histórico, contentor das grandes obras de arte do passado, mas passa agora a estabelecer-se numa contemporaneidade autônoma. É desde logo pensado todo o acesso a este novo edifício de forma geral, com grande número de espectadores, não se questionando tanto a qualidade do seu estrato socioeducativo, mas privilegiando sempre a capacidade quantitativa no seu acesso.

A questão do referencial volta a impor-se, porém como ruptura. Todos os exemplos dados foram polêmicos no seu tempo, na medida em que se estabeleciam perante à cidade como descontinuidade. O edifício passa a valer por si. Deixa 
de ser apenas válida a monumentalidade dos mosteiros e dos palácios, para se marcar uma nova era.

A monumentalidade é ainda escultórica, mas o poder que representa distingue-se pela idéia - ilusória ou não - de que todos fazemos parte. Revemo-nos e identificamo-nos com o espaço e com o outro, que visita esse mesmo espaço tal como nós.

A polêmica decorrente da ruptura, no momento de materialização dos edifícios, é de certo modo atenuada por esta ideia do acesso livre, que leva o maior do saudosista a alienar-se do seu questionamento, perante a possibilidade da democratização do espaço de cultura.

\section{Da cidade tradicional à periferia veloz}

A par dessas obras que marcaram o final do século XX, foi-se ainda observando uma geral e crescente descentralização. Iniciada, como vimos, em tempos de crescimento das periferias e expansão dos centros urbanos, surgida com revolução industrial e falta de capacidade das cidades tradicionais darem resposta à bolha populacional, este novo entendimento do quotidiano vai trazer até aos dias de hoje uma crescente descentralização dos centros tradicionais cívicos, de comércio e serviços. Será inevitável que essa condição não se aplique em todas as vertentes e dimensões socioindividuais.

Se na era em que a máquina a vapor foi se estabelecendo nas cidades, com condicionamentos que se prendiam com percursos em linha reta e que implicavam a inexistência de grandes declives e ângulos fechados no seu trajeto, estabelecendo-se como foco de nova fixação de comércio, habitação e serviços, junto à cidade baixa, a maior parte das vezes em contradição com os grandes morros onde as cidades medievais se estabeleciam, também com os novos acessos surgem como novas formas de centralidade.

As grandes estruturas que surgem com a pós-modernidade, acompanham a fixação fora da cidade tradicional, com especial ênfase junto às principais vias de comunicação e deslocação. É junto a essas grande vias de transito rápido que vão sendo criadas as grandes estruturas de comércio e serviços, favorecendo a qualidade quotidiana dos habitantes destes territórios.

Um novo paradigma ascendente estabelece-se com uma deslocalização dos espaços sociais e públicos para as grandes superfícies, que passam a trazer qualidades nas suas vivências, nunca antes vistas. 
A par das grandes vias de acesso pendular para dentro e fora da cidade tradicional, são também criadas grandes estruturas que se ancoram nestes traçados e referenciam a paisagem transitória, em especial através do planejamento de grandes superfícies comerciais.

Surge assim em Portugal a primeira cadeia de hipermercados, o Continente inaugurado em Matosinhos em 1985, que vem revolucionar o acesso ao produto e democratizar o espaço de consumo, tendo em conta o bem estar do seu cliente. Essa seguiria já o exemplo consumado por outras grandes periferias de grandes cidades ocidentais, europeias e norte-americanas.

A importância deste novo paradigma prende-se com o entendimento, mais uma vez da identificação do "eu" com o "outro", fazendo parte integrante de algo que nos une num espaço, num conceito e numa postura. Este aparente bem estar, vem atenuar um estado de desorientação que se vive nos climas de pós-guerra e do entendimento de uma condição efêmera perante a desilusão da era tecnológica que deflagra com os acidentes nucleares de 1945 e o holocausto nazi da $2^{\underline{a}}$ grande guerra, entre 1933 e 1945.

Este novo espaço de consumo vem impor-se na paisagem com grande força pela sua dimensão e volta-se totalmente para dentro. A sua exterioridade pouco importa. A luz natural é supérflua e quanto mais impermeável for a relação do interior com o exterior, melhor.

O clima é agradável e as suas oscilações são mínimas, prendendo-se muito mais com os picos de afluência ao local do que com aspectos visuais e térmicos. É como se esta linearidade temporal e climática fosse também ela igualitária no sentido em que abrangeria todos os seus visitantes e clientes de forma igual.

\section{Estudo de um caso dissimulado ${ }^{3}$}

Tendo como objeto de estudo o próprio NorteShopping, que no decorrer da expansão do Continente de Matosinhos, se torna em 1998 o maior Centro Comercial do Norte de Portugal e um dos mais modernos da Europa, surge quase que de forma automática um súbito interesse por esta dinâmica estabelecida entre um fluxo de habitantes da cidade tradicional e daquilo a que se passa a chamar de Grande Porto.

Ao longo de toda a estrada para Norte surgem novas centralidades que vêm alterar costumes das povoações mais rurais, estabelecer postos de trabalho e instaurar novas tipologias de espaço público. 
O interesse pelo NorteShopping, no entanto não é gratuito. Quando planeado, a existência de um parque de estacionamento na cobertura, que viesse a aproveitar a superfície mais elevada como ponto de paragem, é também pensado um acesso em aspiral que vencesse a altura imposta pela estrutura.

É aqui estabelecida pela primeira vez uma possibilidade singular, a da criação de um espaço cultural, que vem dar apoio ao de lazer, comércio e serviços, a que se liga.

Seguindo a premissa generalizada na concepção de centros comerciais, também o Silo Espaço Cultural do arquiteto Eduardo Souto Moura, se volta para o interior, criando uma relação que se anula com a sua envolvência. A entrada de luz zenital, vem, no entanto, pontuar temporalmente o ciclo horário/diário, que ora permite uma iluminação morna e tênue para o interior, ora pontua no exterior a existência de um elemento habitável, no interior do silo-auto que o rodeia, como um farol no horizonte.

Acompanhando o mesmo conceito ditado pela entrada de luz zenital, que permite certo estado de serenidade e aconchego, também o revestimento interior, em tijolo refratário, vem tornar essa mesma envolvência mais marcada. $\mathrm{O}$ calor do material e da cor avermelhada do mesmo, permite entender o espaço como um invólucro, assemelhando-se, apesar da discrepância da escala, à dimensão do espaço uterino conseguido pelo Museu Solomon R. Guggenheim de Nova Iorque, do arquiteto Frank Lloyd Wright (1959). Essa dimensão de fechamento sobre o seu interior, com entrada de luz pela cobertura, permitindo um percurso lateralizado à superfície continua que o compõe, vem traduzir-se num estado apoteótico que permite ainda uma elevação reflexiva e introspecção.

A colocação do material no seu interior, por meio da característica paralepipédica do material na constituição de uma parede circular, é encaixada de forma desencontrada, mas cadente, que conciliada com a luz da cobertura, cria um espaço texturado, dinâmico, mas acolhedor, transmitindo estabilidade e segurança.

O seu acesso é feito pelo NorteShopping, surgindo à primeira vista como que um dos acessos de cargas e descargas, de entrada condicionada, existente em todos os centros comerciais. A sua disposição perante à estrutura principal apresenta-se a meio do corredor de roupa e artigos de bebê e criança e de frente ao seu corredor de acesso, surge um espaço recreativo infantil, com escorregas e piscinas de bolas. Todo esse aparato camuflado parece estabelecer-se como elemento de filtragem ao seu acesso. Uma 
pequena referência ao espaço é colocada na frente do corredor por onde o percurso se faz, sempre com a imagem da exposição em vigor, numa composição conceptual e letras amareladas, que se esbatem na própria luz do NorteShopping.

A escala do acesso ao espaço cultural é reduzida quando comparado com toda a estrutura presente no centro comercial. Uma via estreita e pouco nobre, com um referencial ao fundo composto por duas portas simétricas, de aspecto metálico com dois postigos circulares em vidro, que lembram as alas fabris ou hospitalares. Na lateral deste reduzido passadiço, vê-se escrito de forma discreta a sua sinalética, como que em tom de aviso eminente de entrada no mesmo. "SILO ESPAÇO CULTURAL", vê-se em letras amareladas e, apesar da sua estridência, esconde-se de quem circula pelo espaço comercial.

A porta dupla metálica representa uma passagem para uma exterioridade industrializada, que se abre, não para o espaço cultural, mas para um espaço exterior por onde é necessário passar para aceder efetivamente a este. Entre a porta do centro comercial e a entrada no silo, temos uma passadeira que atravessa o acesso ascendente ao parque na cobertura. Nessa travessia é possível encarar o capeamento do silo. Em betão ${ }^{4}$ aparente, com aspecto marcantemente industrializado, quase se reduz à sua dimensão estrutural e à função que se lhe encontra associada, com uma nova porta dupla inscrita na superfície do cilindro, à semelhança da inicial.

Essa dimensão, quase que em bruto e com alguma rudeza, vem contrapor-se com a sensibilidade da linguagem do interior do silo.

Totalmente voltado para dentro, a sua impermeabilidade isola o seu utilizador do caráter industrial do exterior, que se prende com a mobilidade automóvel e acesso massivo à estrutura mãe a que ancora.

Podemos assistir, mais uma vez, à ideia de democratização da cultura que se aproxima cada vez mais de um público tão diverso quanto possível. Neste caso, observamos ainda um exemplo singular daquilo que é a formulação tipológica convergente, que pretende albergar num mesmo espaço o máximo de tipologias de uso, permitindo ao seu público um total conforto na sua utilização e ainda, por parte do seu promotor, a certeza de que esse mesmo público não necessitará sair dessa grande estrutura para procurar numa outra algo que deseja.

Apesar dessa aparente intencionalidade, observamos uma filtragem singular do acesso ao espaço, através da redução da sinalética, da diminuição clara da escala do seu acesso, linea- 
ridade de linguagem industrial entre a travessia pedonals e o acesso ao estacionamento e ainda, a própria dissimulação do espaço como miolo, que passa facilmente despercebido.

É importante referir a forma como o espaço é pertencente à estrutura mãe, mas colocado fora de si mesmo. É disposto de fora periférica em relação ao edifício principal e à sua função. A realidade é que uma maioria significativa não visitou nunca o silo e que nem tampouco reconhece a sua existência.

A monumentalidade do espaço de que se falava inicialmente é aqui camuflada pela função que está na ordem do dia, a da mobilidade e do acesso democrático aos espaços de consumo. É uma monumentalidade industrializada que não implica necessariamente a existência de um espaço que lhe seja interno.

A questão da democratização do conhecimento e do saber é hoje abrangente e fluente, não se conhecendo barreiras entre aquilo que é o conhecimento cultural da galeria e o cultural da 'culturalidade' de um povo, cada vez mais homogêneo.

As barreiras formais são evidentes e, aquilo a que se assiste, é a uma despopularização deste mesmo espaço, que em contradição com aquilo que existe, por exemplo, em Miguel Bombarda, pretende permanecer-se como que à margem daquilo que é uma cultura pop, de desfile e mesclagem.

A forma de periferização do projeto inicial é, portanto, persistente no programa a que se assiste, e a verdade é que o acolhimento a que se acede no interior do Silo Espaço Cultural depende de certo modo desta filtragem e é a partir dessa mesma 'seleção' que se permite um estado introspectivo, quase que familiar no seu interior.

A referência espacial surge aqui não plasmada na paisagem, mas como que pertencente ao imaginário do que conhece esse mesmo invólucro. A questão do poder não se encontra então agora marcada como ao longo de toda a história se observou com demarcações visuais e físicas, mas numa tênue linha imaginária entre um conhecimento 'especializado' e outro, 'globalizado'.

\section{NOTAS}

1. Referência ao texto Sculpture in the Expanded Field, de Rosalind Krauss, originalmente publicado no número 8 de October, na primavera de 1979 (pp. 31-44).

2. Referência à obra de Jean Baudrillard "L'effet Beaubourg" (1977), centrado na ideia de "máquina cultural" revolucionária e progressista. não ter o que se tem, em contrapartida com a "simulação" que se refere ao ter o 
que não se tem. No primeiro caso refere-se a uma presença, enquanto que no segundo se prende com uma ausência. (Simulacres et Simulation, P.9, 1981).

4. Trata-se de uma palavra de Portugal e se refere à mistura.

5. Trata-se de uma palavra de Portugal e se refere a restrito para pedestres.

\section{Referências}

AUGE, Marc. El tiempo en ruínas: Barcelona: Gedisa Editorial, S.A., 2003.

BAUDRILLARD, Jean. La Societé de Consommation: ses mythes et ses Structures: Paris: Gallimard, 1970.

BAUDRILLARD, Jean. Simulacres et Simulation: Paris: Galilée, 1981.

BHABHA, Homi. O Local da Cultura: Belo Horizonte: Editora UFMG, 1998.

COSTA, António Firmino da. Dos públicos da cultura aos modos de relação com a cultura: algumas questões teóricas $e$ metodológicas para uma agenda de investigação: AA.VV, Públicos da Cultura. Lisboa: Observatório das Actividades Culturais, 2004.

DEBORD, Guy. La Société du spectacle: Paris: Gallimard, 1967. DEBORD, Guy. Theory of the Derive: Les Lèvres Nues \#9, 1956. FOUCAULT, Michael. A Ordem do Discurso: Curitiba: Loyola, 1970.

LIPOVETZKY, Gilles. A Sociedade da Decepção: Lisboa: Ed. 70, 2010.

LIPOVETZKY, Gilles. Serroy, Jean. Cultura Mundo: Lisboa: Ed. 70, 2010.

MAFFESOLI, Michel. El-Tiempo de Las Tribus: El Declive Del Individualismo en Las Sociedades de Masas: Barcelona: Icaria Editorial, 1990.

MAFFESOLI, Michel. La Violence totalitaire: Paris: Presses Universitaires de France, 1979.

RANCIÉRE, Jacques. Le spectateur emancipe: Paris: La Fabrique, 2008.

Recebido em: 24/02/15

Aceito em: 06/05/15 


\section{INÊS ALVES}

inesteixeiraalves@gmail.com

Licenciada em Arquitectura (ESAP, 2008) e Mestre em Arte e Design

para o Espaço Público (FBAUP, 2011), doutoranda em Educação Artística na Faculdade de Belas Artes da Universidade do Porto. A sua atividade acadêmica centra-se na preocupação com os novos propósitos da Arquitetura, no crescimento da cidade e entendimento dos territórios mais periféricos como palco de alterações humanas e sociais drásticas, com o emergir do pensamento Pós-Moderno. 